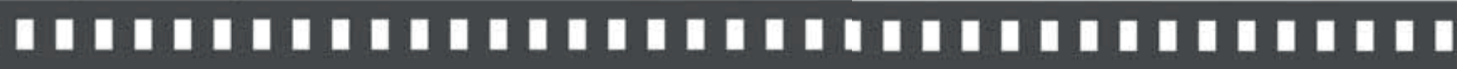

\author{
Estado del Arte sobre la investigación \\ en cine latinoamericano y colombiano. \\ Estudio de caso: 2005-2015
}

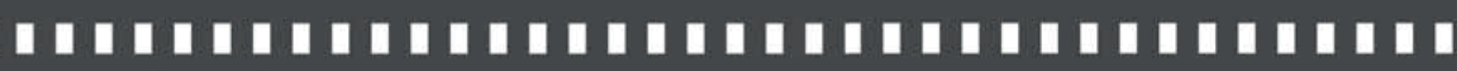

Carlos Fernando Alvarado Duque

Artigo recebido em: 15/05/2018

Artigo aprovado em: 16/04/2019 


\title{
Estado del Arte sobre la investigación en cine latinoamericano y colombiano. Estudio de caso: 2005-2015*
}

\author{
State of the art about the research in latin american and \\ colombian cinema. Case study: 2005-2015
}

Carlos Fernando Alvarado Duque**

\begin{abstract}
Resumo: Este artículo ofrece un mapeo sobre al estado de la investigación fílmica en el ámbito latinoamericano y colombiano entre los años 2005 y 2015. Desde la perspectiva cualitativa de los -Estados del Arte- analiza artículos y tesis doctorales relevantes para concluir que, desde geografias, épocas, representaciones y discursividades heterogéneas, el conocimiento producido, aunque revela la emergencia de nuevas estéticas, muestra una baja producción intelectual que supone dependencia de la tradición hegemónica en el marco de las Ciencias Sociales.
\end{abstract}

Palavras-chave: Cine latinoamericano. Cine colombiano. Estudios sobre cine. Representación cinematográfica.

\begin{abstract}
This article offers a mapping around the state of the filmic research in the Latin-American and Colombian context in the years 2005 and 2015. From the qualitative perspective of -the states of the art-it analyzes articles and doctoral thesis relevant to conclude that, from geography, ages, representations, and heterogeneous discursivities, the knowledge produced, although it reveals the emergency of new aesthetics, shows a low intellectual production that suggests a
\end{abstract}

\footnotetext{
* Este artículo está adscrito de la línea de investigación en Estudios sobre cine perteneciente al Grupo de Investigaciones de la Comunicación de la Escuela de Comunicación Social y Periodismo de la Universidad de Manizales, Colombia (2017).

** Doctor en Filosofía. Profesor de la Escuela de Comunicación Social y Periodismo de la Universidad de Manizales.
} 
dependency of the hegemonic tradition in the social sciences framework.

Keywords: Latin-American cinema. Colombian cinema. Film studies. Cinematographic representation.

\section{Introducción}

Los estudios sobre cine se han decantado, en principio, por el análisis narrativo y estético que privilegia a la imagen y al montaje (escritura en imágenes) como focos centrales de estudio. Con ello se da paso a una revisión del relato (que supone un problema representativo) el cual permite un puente con diferentes referentes que escapan a las formas fílmicas. Esto abre un abanico de lecturas que cubren los análisis estructurales, el universo de la ficción, el estudio de cinematografías particulares, autores, movimientos, géneros, hasta los impactos que el séptimo arte genera en las sociedades actuales. Si bien son muchos los puntos de vista, se ha privilegiado el hecho que, por lo general, el séptimo arte opera como medio narrativo. Como sugiere Metz (2002), el cine perpetra en calidad de relato con una doble secuencia temporal (narración y enunciación) que da pie a representaciones documentales o ficcionales. Y esos modos de narrar bien pueden optar por continuar un estilo hegemónico (Hollywood) o asumir posturas críticas o alternativas (vanguardias, cines independientes). De la misma manera, se reconoce en el cine un fenómeno semiótico; como bien señala Echeverri (2008), gracias a que impulsa a la interpretación de signos y códigos que permiten comprender la capacidad de producir sentido en un lenguaje no verbal que, a la vez, invita al 
doble sentido propio de un acercamiento hermenéutico.

La producción de teorías sobre el cine en Latinoamérica, como reconoce Zavala (2009), no ha rendido mayores frutos, a pesar de una larga tradición investigativa, por la insularidad interna (formas reducidas de circulación), la insularidad externa (cerramiento de fronteras conceptuales e influencia anglosajona) y la insularidad disciplinar (dependencia de las ciencias sociales y poca aproximación humanística). Es importante advertir que las teorías sobre cine nacen con el cine y, a la par, la filosofía se interesa por su estudio diferenciando dos posturas: el cine como arte y el cine como técnica-industria. En ello, es significativa la influencia de las corrientes estructuralista-semiótica y psicoanalítica que hacen meya en estos marcos conceptuales al permitir abrir campo a su estudio académico. Su interés inicial se concentró en la estructura del séptimo arte (imagen, sonido, montaje, etcétera) ligada a procesos ideológicos y políticos, y a dinámicas de género (década de los 70'). Se da, así, paso de preguntas ontológicas (¿qué es el cine?) a preguntas que incluyan al espectador y la experiencia estética (respuesta emotivo-cognitiva). Preguntas que implican interacciones entre la sensibilidad del espectador y la producción cinematográfica (giro teórico). Parafraseando a Castellanos (2007), el cine como experiencia estética, en tanto construcción poética, busca controvertir el pensamiento humano.

Es de considerar que la experiencia poética a través del cine, re-significa las vivencias cognitivo-emocionales al permitir abrirse a otras racionalidades para problematizar el mundo de la vida. Por ello, se puede entender que las teorías del cine más contemporáneas no se interesan tanto por el relato como tal, sino 
por cómo la producción misma hace sentir y pensar (a partir de lo representado en el filme); es decir, se ausculta por la producción de otros discursos y sus impactos concretos. Esta pegunta, para al presente ejercicio investigativo, apunta hacia el interés por decantar el conocimiento del amplio campo de estudio sobre el cine latinoamericano y colombiano en los últimos años con el fin de reconocer su valor estético-cultural.

Ahora bien, con la intención de hacer un mapa sobre la investigación filmica en la región, se hace una revisión de la literatura producida en los últimos diez años: resultados de investigación publicados en revistas y registrados en fuentes de circulación masiva (Web), y tesis doctorales divulgadas directamente en Internet (capturadas de bases de datos de difusión en español). Se observa que en el último quinquenio el grueso de la producción bibliográfica corresponde a un $69 \%$ de textos analizados; igualmente, se registra un notorio descenso entre los años 2005 y 2008 (11\% de la producción estudiada). Po su parte, los años 2009-2010 parecen marcar un punto de re-vitalización del cine como objeto de conocimiento.

La metodología para esta investigación corresponde a la modalidad de los Estados del Arte que permite la recuperación del conocimiento acumulado. Como trabajo cualitativo se matricula en la vertiente hermenéutica que ofrece la posibilidad de interpretación en relación con el contexto puntal de la época para hacer, aquí, una primera lectura textual desde el abordaje de 131 documentos, de 220 rastreados (seleccionados mediante el método de saturación teórica).

Es de recordar que aunque por varios años se ha augurado la muerte del cine, este vaticinio, por el contrario, es un registro de 
su empuje. El cine sigue siendo parte importante del imaginario social de la vida cotidiana de toda sociedad y un continuum cultural por su función comunicativa. Su fuerza radica en la relación erótica - simbólica - mediática. De ahí que el cine, como objeto de conocimiento, en tanto dispositivo tecnológico-cultural de comunicación e interacción social, supone un acto de reflexión para visibilizarse como una herramienta que opera en procesos de construcción de realidad.

\section{Cruce teórico-empírico de los estudios sobre cine ¿Hacia una demarcación endógena?}

El análisis estético del cine se ha interesado, a lo largo de los años, por actualizar, primero, las posturas propias de la ilustración (preguntas por la forma y el contenido, la belleza, los procesos de verosimilitud, la duplicación de un referente, el papel del artista, etcétera) y, segundo, por crear un arsenal conceptual, aparentemente propio, para delinear las dinámicas del séptimo arte. Se dice aparentemente, en este caso, porque si bien se han hecho aportes significativos, son siempre en la línea de reciclar ideas y categorías de otras artes. De este modo, el concepto de imagen en movimiento es propio de la relación entre pintura y ciertas artes de la acción como el teatro. Lo mismo puede decirse de conceptos como puesta en escena con connotaciones tanto teatrales como operáticas. La idea de montaje, supuestamente cinematográfica, es propia del teatro y también de la literatura.

En esa medida, es importante señalar que la estética contemporánea adquiere múltiples caras ya que toma distancia del 
arsenal conceptual clásico, al efectuar variaciones en el dispositivo teórico. Ello lleva a nuevos modos de comprensión de la práctica fílmica gracias a un viraje-desplazamiento de un sistema conceptual institucionalizado. Sin sugerir que la visión clásica sea caduca, se cree que no se puede decir de otro modo sino se cuestiona sus propios mecanismos de análisis. En tal contexto es clave el esfuerzo contemporáneo por una expansión que no reduzca la estética a un análisis de la obra de arte. Una estética expandida estudia el modo en que todo sistema material es capaz, en términos sensibles, de dar paso a un sistema de enunciación (una suerte de vínculo estésicosemiósico, como sugiere Mandoki, 2006).

De este modo, los estudios sobre cine, en términos estéticos, operan sobre las que son, quizás, las categorías más tradicionales en el análisis cinematográfico: imagen y montaje. La primera se interesa por el modo en que se construye el cuadro fílmico como un espacio fotográfico-pictórico. La segunda se interesa por el proceso de encadenamiento de imágenes (por eso depende de la primera categoría) en una especie de línea imaginaria que supone un sistema causal que, en términos temporales, apunta hacia un futuro. Sobre ambas se han tejido gran parte de las explicaciones estéticas del cine y, tras de ellas, se han intentado diversas defensas de sus cualidades artísticas.

En términos de ubicación, el cine latinoamericano, de cara al auge de otros medios masivos de comunicación como la televisión (y viceversa), decrece en los años 70 y 80 . Este dato es significativo porque, de algún modo, impulsa al séptimo arte a concentrarse en una suerte de función social como mecanismo de representación de su contexto. Tiene lugar una filmografía que muestra otras formas 
de configuración de la realidad. Puede reconocerse la aparición de un "cine fronterizo", con temas emergentes, que pone al descubierto marginalidades sociales, ciudadanías clandestinas; un cine político ya no militante sino intimista, comprometido (connotación éticaestética y pragmática) con relatos cotidianos y otros retratos de la construcción de identidades (otras violencias y pobrezas). Se da el paso de discursos liberales y socialistas, a discursos pluralistasdemocráticos en el marco de lo privado en la escena pública.

Valenzuela (2010), a partir de sus trabajos sobre el cine latinoamericano, registra el paso de una macro-política a una micropolítica en la filmografía de la región que pone en primer término a los sujetos para cuestionarlos de cara a un sistema político en crisis, a una sociedad que necesita cambio. Se ponen en pantalla, nos dice, sujetos marginales que deambulan en territorios desdibujados, cuerpos en permanente tránsito (de rostros, de costumbres, de idiosincrasias, de aprendizajes, de imaginarios de vida y muerte). Para este pensador, el nomadismo es el rasgo central del cine latinoamericano, desde los años 60' hasta el presente, lo cual revela el paso de una ideología militante a una politización del diario vivir (giro de la movilidad - cine marginal). Como señala Amiot (2007) se registra un cine latinoamericano basado en historias nimias interesado en lo cotidiano con argumentos intimistas.

El cine latinoamericano en los últimos 50 años, gracias a exploraciones estéticas, da paso a nuevas narrativas fílmicas, como sugiere Zavala (2009), herederas de la tradición humanista anglosajona de corte inductivista-pragmático con un marcado interés político en la cultura popular. En contra de una postura positivista, por las influencias ya señaladas anteriormente, la investigación 
sobre este contexto cinematográfico opta por una hibridación epistemológica y discursiva, con influencia del pensamiento francés, que estudia las tendencias estéticas del séptimo arte (retratos íntimos y a testimonios de conflictos socio-políticos). No obstante, la prevalencia de la investigación historiográfica se hace significativa (últimos años) con un especial interés por las formas en que el cine reconstruye las diferentes realidades en una geo-textualidad (cada territorio se convierte en un texto que puede ser leído).

En general, se puede afirmar, según la revisión documental (investigaciones sobre el mundo del cine), que los estudios en esta área y en diversas regiones del mundo (Europa, Asia, Japón, China, Alemania, Rusia, Australia, Norteamérica, Canadá, Centroamérica, Suramérica, India, Irán, entre otras) se concentran en los nuevos lenguajes audiovisuales del siglo XXI, la relectura a los clásicos (desde otras estéticas y poéticas), las nuevas narrativas fílmicas, el autor, su obra y las representaciones cinematografías (incluyendo en este último campo un espacio relevante para los estudios historiográficos y al cine de denuncia). Se observa cómo los análisis sobre el cine a nivel internacional utilizan de base un fuerte corpus teórico el cual, a su vez, es el soporte de los análisis fílmicos en América Latina. Dicha situación muestra una producción intelectual baja (conocimiento de punta) que sirva de referente teóricos para los estudios en cine latinoamericano. En términos de Zavala (2009), esto obedece a tres vertientes o insularidades: una interna dada la debilidad en las políticas de difusión y promoción del material bibliográfico; otra externa a razón de la marcada dependencia de la tradición anglosajona; y una disciplinar que responde a la dependencia teórica de las ciencias sociales de corte empírico, 
distantes de la tradición humanística-filosófica-crítica (menos del $90 \%$ de los registros).

Desde la anterior perspectiva, en la década del 2005 al 2015, se observan rupturas con la segunda insularidad para dar paso a un alto volumen de investigaciones (es decir, libres del modelo anglosajón) pero todavía en co-dependencia de las ciencias sociales (mirada disciplinar). Sin embargo, se ha permitido superar el constante interés por las indagaciones historiográficas para abrir el abanico a problemáticas socio-humanistas con un tratamiento cualitativo o hermenéutico/fenomenológico en términos investigativos. Se privilegian, en calidad de categorías de análisis, conceptos sociolingüísticos y acercamientos a las representaciones cinematográficas de la realidad. Los estudios de indicadores de consumo, públicos y recepción son menores (pocos son los trabajos publicados sobre producción y promoción fílmica). Es de reconocer que el área socio-lingüística, como objeto de conocimiento en torno a prácticas fílmicas y recursos textuales, es baja (27\%) y tiende a privilegiar el cruce disciplinar (estudios de cine y otras áreas del conocimiento).

Ahora bien, se hará uso de la clasificación de Casetti (1994) para analizar el entramado conceptual con que se ha estudiado el cine en Latinoamérica y Colombia, siendo conscientes de la dificultad de hacer una taxonomía precisa ante el cruce de múltiples variables y categorías investigativas. El autor propone cuatro campos de análisis para la producción teórica sobre cine como: 1) industria cultural (aspectos de recepción y consumo con 2.97 de los estudios); interés en la relación cine-públicos o estudios de recepción del cine (análisis de los contextos de consumo); 2) industria socioeconómica (aspectos artísticos abordados como mercancía con 
la supremacía de factores económicos con $3.70 \%$ de los casos); interés en el mercadeo a través de los sistemas de financiación y rentabilidad del cine (análisis de distribución y divulgación); 3) institución socio-estética (aspectos socio-lingüísticos); interés en la discursividad o formas de configuración del discurso fílmico expresado en sus poéticas (análisis de la construcción del film frente a sus recursos textuales con $27.40 \%$ de las indagaciones), estéticas (análisis de las formas de implementación de los lenguajes fílmicos) y narrativas (análisis de los relatos como mecanismos capaces de producir mundos de ficción); y 4) representación de lo social (aspectos especulares de la puesta en obra de una realidad con un 57.03 de las producciones); interés en el conocimiento sobre los procesos de construcción de realidad o vínculos con otros sistemas de representación.

Es de anotar que la literatura no reporta una única taxonomía o definición de áreas, campos o líneas de conocimiento y no hay claridades conceptuales frente a algunas de las categorizaciones propuestas. Un caso es la tipificación del Ministerio de Cultura y Dirección Cinematográfica de Colombia, y la Universidad Nacional y el Instituto de Investigaciones Estéticas (ROJAS, 2009). En ambas propuestas de clasificación se observa un eclecticismo conceptual en tanto se ubica en la misma línea temas, campos disciplinares, objetos/problemas de conocimiento y perspectivas teóricas y metodológicas de análisis. Igualmente, amalgama, en forma desestructurada, las líneas propuestas por Casetti. Así, proponen 25 líneas o áreas del saber que bien pueden clasificarse como sublíneas o ejes-temáticos de indagación y que, para esta exploración, se categorizan dentro de las cuatro vertientes teóricas. 
Puede agregarse, que existe una correlación entre las líneas teóricas propuestas por Casetti (1994) en torno al análisis fílmico y la evidencia empírica encontrada (textos analizados sobre al estado de la investigación: 2005-2015) sobre los resultados de estudios en la materia (circulantes en la Web). En ella se resaltan algunas sub-líneas de conocimiento delimitadas por el mismo registro ideográfico, lo cual hace pensar en una mirada polifacética al cine desde el campo de las ciencias sociales, en general (mayor soporte teórico), y humanístico en particular, sin descartar la vertiente socio-económica (menor prevalencia). El mayor porcentaje de investigaciones se ubican en la línea de re-presentaciones cinematográficas, siguiéndole en su orden los estudios relacionados con aspectos socio-lingüísticos (recursos estéticos, poéticos y narrativos).

Es importante tener presente que se registran dos categorías de análisis por fuera de estas líneas, una que hace referencia, propiamente, a la investigación sobre la investigación o Estados del arte (4.45\% de los casos) y otra sobre el valor didáctico del cine, como recurso para la enseñanza (4.45\% de los estudios). No se desconocen los estudios asociados a la relación cine-poder (realizaciones fílmicas como herramienta para el cambio social) o cine de denuncia, el cine como un escenario para la expresión cultural, y el cine como lectura sobre acontecimientos históricos, los cuales se ubican en la categoría de representaciones. De la misma manera, deben destacarse los estudios en el campo de adaptaciones literarias o la relación cine-literatura que encaja en la categoría aspectos socio-lingüísticos.

Vale la pena hacer un paréntesis para señalar que, directamente en la línea de los estudios culturales, la prevalencia de 
producción de conocimiento en torno al cine como un dispositivo de mediación cultural en procesos de socialización humana es baja. Existe un alto interés por indagaciones en el campo de las re-presentaciones o de los aspectos de construcción de la imagen en torno a la cultura en una sociedad dada, contrario a lo que vaticina Gorham (GARCÍA, 2000) quien sugiere que se destacan los estudios sobre consumo y recepción. Casi se podría asegurar que la línea de representaciones encajaría en el campo de estudios culturales, a pesar de que se registran, de acuerdo al autor, en la línea económica, lo cual reduce el contexto de definición a prácticas comunicativas capitalistas (indicadores de audiencia).

Las investigaciones realizadas sobre una problemática endógena o exógena no muestran necesariamente correspondencia con el lugar de origen de sus investigadores (desde donde se produce el conocimiento); por ejemplo, varios estudios sobre cine latinoamericano o colombiano son elaborados desde diferentes latitudes geográficas, o algunos estudios sobre cine de autor y/o épocas son más universales y no muestran, de igual forma, relación directa con el origen de su producción. Particularmente, se han plasmado algunos Estados del conocimiento sobre el cine latinoamericano y colombiano, los cuales recogen un periodo y un objeto particular de indagación que ofrecen resultados, particularmente cuantitativos, del saber acumulado en el área (lo escrito, en esta caso, desde los resultados mismos de las investigaciones). Son estudios que compilan y sistematizan información pertinente para dar cuenta de tendencias, categorías y avances de la información o conocimiento generado (toman los resultados de investigación como unidad de análisis). 


\section{El cine Latinoamericano Retratos Cotidianos}

No solo los Estados del Arte sobre cine latinoamericano sino estudios geo-epocales configuran un mapa de la investigación que se concentra en tres categorías: Historiografía, Representaciones y Análisis semio-lingüísticos (CARRO, 1997; DOLL, 2012; GÓMEZ; ROSELLÓ; GONZÁLEZ, 2011; LILLO; CHACÓN, 1998; STANGE; SALINAS, 2009; ZAVALA, 2009; PARADA, 2011; entre otros). Cabe, así, señalar que la producción fílmica tiene mayor concentración en países como México, Argentina y Brasil (responsables del 89\% de la producción cinematográfica en la región, según Guilherme [2008]), con una tendencia, en el siglo XXI, como expone Valenzuela (2010), a dar cuerpo a una filmografía que transita de los discursos macro-políticos a los micro-políticos, la cual rompe con las clásicas posturas hegemónicas (como ya se ha visto en la filmografía mundial) para ofrecer una mirada desde lo endógeno, intercultural y transnacional. Un cine leído desde la "metáfora del laberinto" (LÓPEZ; VERGARA, 2009) que apunta al "arquetipo del no-lugar" (VALENZUELA, 2010), del trasegar permanente, del nómada en la "fusión andante/paisaje". En síntesis, un cine que busca abrir caminos, un cine inacabado a partir de historias mínimas.

Se observa una alta preferencia por el tema de la recuperación histórica (80\% de los trabajos, según Zavala, (2009)) que, para el siglo pasado, se complementa con estudios de directores y géneros (perspectiva historio-sociológica). En el siglo XXI, la constante son los temas micro-políticos (representaciones) y los 
estudios humanísticos y culturales (a partir del 2006 se incrementa el interés por la investigación), como ya se mencionó. En segunda instancia, se reconoce el interés de exponer las identidades nacionales desde historias mínimas (no-oficiales), un fuerte intento por la reconstrucción de la vida social con un grado destacable de experimentación estética. No obstante, señalan Stange e Salinas (2009), no se vislumbran grupos académicos articulados que ausculten el cine, por lo tanto no hay un campo de estudio definido (temáticas dispersas).

Como rasgo significativo, se puede sugerir que el cine latinoamericano tiene un marcado tono heterogéneo, no está organizado como un movimiento o una escuela a razón de su fuerte complejidad y diversidad. En términos de representación, no se reconoce una propuesta estética que rompa con las dominancias culturales; que revele una postura política crítica, comprometida con otras lecturas de lo social. Su inclinación sobre los modos de construcción de la cotidianidad se aleja de un norte como el anterior, para representar la vida de ciudadanos del mundo, des-localizados de sus propias geografías.

Al parecer el objeto de estudio del cine latinoamericano se ha concentrado, según Gómez, Roselló e González (2011), en la dicotomía acción política y elección estética, tensión heredada de las narrativas de las décadas del 60' y 70'. El paso de un cine militante, en gran parte restringido por las mismas políticas de producción (formatos ilegales a los ojos del escenario formal ante el control dictatorial), a un cine social de historias mínimas pone en obra esta disyunción. Y, así, la clásica polémica entre documental y ficción, que es tan política como estética, tiene relevancia en 
la escena latinoamericana. Para los autores en mención, todo documental es ficción. En esta medida, el cine latinoamericano pone en obra el espíritu cultural de época como fuente documental histórica que narra la vida social, con una hibridación de géneros y una recursividad fílmica compleja para una sociedad heterogénea.

Se puede afirmar que este cine tiene una tendencia marginal en sus contenidos y un tono melodramático en su representación que lleva lo conduce, por medio de narrativas de amor, al giro de la modernidad periférica (encuentros y des-encuentros afectivos). Se hace presente una realidad interpretada para ser interpretada, a su vez, por los públicos. Sin embargo, no puede olvidarse que las filmografías latinoamericanas han sido influenciada por modelos foráneos (europeos, norteamericanos, otros), como efecto de las dinámicas de la industria cultural y su incidencia en las formas de re-presentación; formas aunadas a los imaginarios de época y a las perspectivas ideológicas de los directores frente a las formas en que la imagen re-produce la identidad de una Nación. No obstante, el interés es hacer una radiografía de la situación del subcontinente, como bien señala Salinas (2010), para abrir las puertas a la reflexión en torno a la objetivación de la realidad "desde los propios lugares de enunciación". Para ello, señala el pensador, se hace inminente la ruptura con las narrativas naturalistas (instrumentales).

Es importante demarcar que el cine latinoamericano ha evolucionado a la par de la sociedad y sus avances tecnológicos dando lugar a seis periodos que aquí se reconstruyen, a partir de las clasificaciones de Carro (1997), Lillo e Chacón (1998), y Parada (2011): 1) silente (1897- década del 20'), cine primitivo y artesanal; 2) sonoro (décadas del 30' al 40'), el melodrama de 
entretenimiento; 3) revolucionario (década del 60'), militantismo político revolucionario (aunque sigue la influencia de Hollywood); 4) comercial (década del 70'), auge hollywoodense ante la represión dictatorial en los países de mayor producción; 5) intimista (décadas del 80' al 90'), nuevos espacios y relatos (contradicción familiar y humor); y 6) minimalista-estético-marginal (siglo XXI), dimensión política implícita, dialogo intertextual y reciclaje de textualidades estéticas. Se incrementa la producción con el paso de los años y se ofrece una re-lectura a los clásicos del séptimo arte que incluye tanto otros géneros como nuevas temáticas.

A manera de síntesis, se puede decir que cualquier filmografía es objeto de estudio en la medida que, al no ser un retrato geo-epocal de un objeto representado mediante un lenguaje textual o discurso, supone el uso de estrategias retóricas o de persuasión con implicaciones no solo ontológicas y epistemológicas sino éticas, históricas, políticas y estéticas. En esta línea son pocos los estudios sobre estrategias discursivas (DITTUS, 2013; GARCÍA; MENDOZA, 2005; entre otros) cuyo interés es el de identificar figuras retóricas en las estructuras narrativas de los filme concretos; insisten los autores que esta perspectiva es utilizable para el abordaje de cualquier tipo de fenómeno textual.

\section{El cine colombiano. Memoria identitaria}

Algunas investigaciones documentales realizadas directamente desde universidades bogotanas y del Ministerio de Cultura - Dirección cinematográfica (ROJAS, 2009; RIVERA, 2011; GARCÍA; MENDOZA, 2005; entre otros) presentan los desarrollos 
en materia del séptimo arte a partir de las siguientes premisas.

La producción cinematográfica, de bajo volumen, se legitima con la ley $9^{\circ}$ de 1942 pero solo logra impulso con la puesta en marcha de la Ley 814 de cine del 2003, lo cual permite hablar de un nuevo cine colombiano. Tras el lento crecimiento del cine nacional en la segunda mitad del siglo pasado, se destaca su amplificación en el siglo XXI. El cine colombiano no es ajeno a las transformaciones sociales y tecnológicas, no obstante se registra una baja asistencia de público ante el cambio de las tecnologías digitales que afectan la forma de ver cine (competencia con la televisión, internet). Ello no impide que se siga considerando, en los diferentes estudios, como uno de los dispositivos mediáticos expresivos más importantes. Se sostiene que el cine colombiano presenta una producción con altibajos y un bajo impacto social, a pesar del reconocimiento de su potencial cultural, fuente de múltiples relatos de país (casos paralelos: Brasil, México y Venezuela).

La primera década del siglo XXI se caracteriza por ser una década marcada por representaciones culturales centradas en valores (derechos humanos, justicia, libertad). Esto da pie a un nuevo cine basado en la visibilización de temas como la marginación, el desarraigo, los problemas íntimos, la violencia, la pobreza, la desigualdad, en síntesis un cine de la conflictividad, del diario vivir, un cine político no militante (rasgo que corresponde con otros casos latinoamericanos). Se destaca la confluencia en problemáticas como el narcotráfico, secuestro, conflicto armado, desplazamiento forzado, la migración, al igual que contenidos como el amor, la pasión por el futbol, la vida del barrio, las relaciones familiares, la realización personal, elementos idiosincrásicos, 
etcétera. La materialización de retratos de la realidad colombiana abandona el modelo objetivista (el cine como espejo de la realidad) para optar por una narrativa de mayor presencia autoral; en palabras de García, uso de estrategias de engaño para un cine que empobrece y se expresa mediante el vaciamiento ético.

El cine colombiano se caracteriza por el cruce de diferentes géneros: comedia, thriller, cine negro, animación, adaptaciones literarias, cine de ensayo, cine documental, etcétera. Resalta, no obstante, el interés del trabajo investigativo por indagar las representaciones que dichas estrategias enunciativas ofrecen (dentro de ellas se destaca el interés del cine por hacer un retrato de la historia). El cine colombiano, en este sentido, parafraseando a García e Mendoza (2005), aún se deja influenciar por la corriente objetivista con las metáforas del espejo y la "lente neutra" y "transparente". Pero dicha influencia, sin embargo, no elimina el tono subjetivista que permite que las obras exploren formas estéticas alternativas (paso de la naturaleza fotográfica del cine a la narración simbólica mediada que reclama el rol activo del espectador como intérprete). El cine, tras una minimización de la representación, muestra "[...] una estética de su degradación" (GARCÍA; MENDOZA, 2005, p. 14).

La identidad del cine colombiano está asociada a la historia de la violencia del país. Se señala, en diferentes investigaciones, que las películas de mayor taquilla orbitan en este referente para ofrecer una imagen de las fracturas nacionales. Esto, claro, supone críticas que sugieren un cine intimista no comercial; no está para operar como cine de la "pornomiseria" u oportunismo mediático, apostilla Rivera (2011). Ello conduce al poco reconocimiento del 
cine colombiano que apuesta por producciones no violentas, con otro tratamiento temático.

Los desarrollos y evolución del cine colombiano, en palabras de Rivera (2011), también han dado lugar a la exploración narrativa, a la construcción de un cine de naturaleza experimental. Tal, no obstante, asegura el autor, es un cine atacado duramente por la crítica por su pobreza de guion y ausencia de una estrategia representativa clara (por lo menos de fácil acceso para los públicos).

Los desarrollos temporales del cine colombiano hacen eco de la evolución misma del cine a nivel mundial. Rivera señala los siguientes periodos del cine nacional: 1) cine de lo bello o cine de deleite poco atractivo para el público (primeras décadas siglo pasado); 2) cine turístico (años 50’ y 60’) que buscó vender la imagen del país con el reconocimiento de la regla narrativa; 3 ) cine político (década del 60’) caracterizado por representaciones de la violencia política y el militantismo ideológico de izquierda; 4) cine popular (años 70’ y 80') caracterizado por el humor en narrativas periféricas - estereotipadas; 5) cine narco (década de los 90’) construido a partir de historias complejas y un fuerte potencial narrativo; y 6) cine experimental o nuevo cine (primeras década siglo XXI) que hace uso de la hibridación narrativa como marca de estilo, una tendencia que da espacio a la figura del autor fílmico. Sumado a ello, gran parte de la filmografía se interesa por retratar las consecuencias de la guerra fruto del conflicto armado en el país. La primera década del nuevo siglo representa el crecimiento de la producción fílmica, según Riviera (2011), si se comparan los 77 filmes registrados contra 19 producidos en la última década del siglo XX.

Es destacable que el inicio de la literatura y bibliografía 
directa (entre ellas la investigación) sobre cine colombiano nace a mediados del siglo XX (ROJAS, 2009), representada en tesis, libros, investigaciones, artículos, ensayos y otros. En el diagnóstico realizado para el Ministerio de Cultura, el autor propone 13 variables (temas) para catalogar la investigación sobre cine en Colombia. Destaca, en orden de importancia, primero la historiografía seguida de estudios estéticos, apreciación cinematográfica y estudios culturales (en los cuales se introducen los análisis de las representaciones cinematográficas y estudios de audiencias); segundo, los estudios sobre producción y circulación; tercero, las disertaciones sobre crítica y análisis estructural (en los cuales se incluyen la indagación semio-lingüística); y cuarto, las observaciones sobre exhibición, distribución y gestión de espacios de difusión. Clasificación que ponemos en correlación con la clasificación de las teorías del cine de Casetti y otros acercamientos al análisis fílmico en otras regiones del mundo.

En síntesis, el estado del conocimiento sobre el cine colombiano en términos de tendencia (en el cual el análisis hermenéutico, semiótico y retórico es limitado) privilegia un acercamiento de tipo fenomenológico-social. Categorías como memoria cultural, identidad colectiva y vida politica, por mencionar algunas de las más recurrentes, revelan el interés por acercarse al cine como espejo del contexto nacional. Muchas investigaciones indagan en este norte, planteando preguntas de este tipo: ¿Cómo se construye la memoria cinematográfica a través de relatos relacionados con el imaginario colectivo, capaces, gracias a las imágenes fílmicas, de afectar la vida individual y social de las audiencias (TORRES, 2006)? ¿De qué manera se reconoce la construcción de identidad 
cultural en las adaptaciones cinematográficas hechas en el cine colombiano (LAVERDE; PARRA; URIBE, 2014)? y ¿Cuáles son las dimensiones políticas del nuevo cine de cara al conflicto nacional (ARIAS, 2013)? Puede decirse que la inclinación a estudiar el cine como mecanismo que refleja la realidad social de la nación potencia su papel más allá del entretenimiento, lejos de su función lúdica. No obstante, son muchas las facetas sociales que no son incluidas en los esfuerzos investigativos dada la concentración en el conflicto político, la memoria y la identidad. Tras de ello, además, el estudio del cine como fenómeno narrativo-estético es reducido y los esfuerzos hechos hasta el momento reclaman un trabajo de largo aliento, y mayor articulación para generar un impacto significativo en términos de producción de conocimiento.

\section{A Manera de Síntesis Conclusiva}

El cine, bien puede decirse, es un complejo dispositivo cultural. Para Latinoamérica (por supuesto Colombia) el séptimo arte, en términos de objeto para los investigadores en cine, bebe en principio de la hegemonía del modelo americano para, con el paso del tiempo, reestructurarlo y cuestionarlo. La distancia con el sistema de representación hollywoodense bien puede leerse tanto en el marcado acento político, como en la fuerza que cobran las narrativas mínimas. No obstante, conforme avanzan las tecnologías digitales, se reconocen ciertas notas comunes con las filmografías del mundo. Bien puede señalarse que la complejidad no permite unificar en una gran categoría estilística a Latinoamérica. Los nuevos contenidos, los diversos recursos textuales y la creación 
permanente de nuevas históricas revelan una dinámica viva en el presente. Existen hitos significativos o rupturas con los discursos hegemónicos que, en muchos casos, recuperan recursos del cine primitivo y reciben influencia de otras cinematografías. Todo ello, desemboca tarde o temprano en las dinámicas globalizantes que igualan los modos de producción pero permiten diferencias textuales-culturales en la representación.

Se puede afirmar que los estudios sobre cine, en la línea socio-lingüística, se perfilan desde una perspectiva endógena (algunos sesgos exógenos), es decir, son estudios que gravitan sobre la propia cultura y que, implícitamente, aportan al conocimiento de su compleja red de relaciones, al develamiento de las prácticas sociales que les confieren sentido para reflexionar sobre las experiencias humana, ya no necesariamente desde una postura política-revolucionaria (análisis estético del pasado) sino desde una mirada política-identitaria (análisis estético de lo cotidiano). En pocas palabras, la producción investigativa en cine en la región se pueden visualizar en cuatro ejes de interés (lo que puntalmente se investiga):

- Geografías, territorios o regiones sobre las que se problematiza/realiza el cine (su investigación se hace desde fuentes Nacionales e Internacionales): Norteamérica, Hollywood, Centroamérica, Latinoamérica (Colombia, Venezuela, Perú, Bolivia, Argentina, Chile, Ecuador), Europa, España, Asia, Rusia, Irán, Filandria, Japón, Australia, otros.

- Épocas, periodos o estratos sobre los que se configura la filmografía objeto de exploración: clásico, post-clásico, 
barroco, moderno, post-moderno, contemporáneo.

- Representaciones o problemáticas y contextos de realidad en el tratamiento cinematográfico: cine y educación, cine y psicología, cine y patología, cine y salud, cine y psiquiatría, cine y filosofía, cine y ética, cine y literatura, cine e historia, cine y música, cine y otros sistemas de representación (construcción de realidad), cine y cultura, cine y violencia.

- Discursividades o recursos semio-lingüísticos, propiamente, con relación no solo a los relatos o historias narradas (gramáticas, retoricas, narrativas, semiótica, hermenéutica, estética, etcétera) sino a los recursos textuales (sonido, planos, imagen, puesta en escena, puesta en serie, ritmos, etcétera) y géneros.

Ahora bien, desde la categoría del cine como institución social-estética, abordada puntualmente, tanto en el cine latinoamericano como en el colombiano, se revela una tendencia más estética-intimista (representaciones desde la esfera privada de la vida de actores en espacios marginales) aunque se podría afirmar que el cine colombiano se demarca más como una propuesta estética-identitaria. Ambos acercamientos poseen una incipiente configuración fenomenológica en su indagación que, para su análisis, amerita dar paso a enfoques semio-hermenéuticos. Se reconoce, al interior de las categorías de análisis de las diversas investigaciones, cierta inclinación a las representaciones sociales en pantalla y un menor interés en los estudios historiográficos y de indicadores de recepción. Sumado a ello es baja la investigación de orden teórico 
cuyo objeto de estudio ofrezca nuevas categorías para comprender el cine como dispositivo tanto expresivo como cultural.

En síntesis, puede enfatizarse que el cine, arqueológicamente hablando, efectúa un simulacro del mundo construido como exteriorización de las propias visiones de los cineastas, filmografías nacionales, etcétera. Se abre la posibilidad de amplificar las versiones estéticas para comprender la realidad latinoamericana en sus diversas aristas, ya sean modos de habitar el mundo, de padecer el paso del tiempo, de configurar el pensamiento, entre muchas más. El marcado interés por el cine como espacio de representación, como reflejo de la realidad, reclama prácticas investigativas que incluyan análisis de tipo estético-semiótico que indaguen, a la par, por los mecanismos sensibles y comunicativos del cine latinoamericano, en general. Los lenguajes-creación también suponen una re-escritura de la realidad social.

\section{Referencias}

AMIOT, Julie. Formas de la ficción cinematográfica actual en Latinoamérica. Cuadernos Hispanoamericanos, Madrid, n. 679, p. 29 - 36, enero 2007.

ARIAS, Juan Carlos. Infancia y conflicto: sobre la tendencia a un cine 'no político' en Colombia. Palabra Clave, Bogotá, v. 16, n. 2, p. 585 - 606, ago. 2013.

CARRO, Nelson. Un siglo de cine en América Latina.

Revolución, polítiCa y Cultura, Xochimilco, n. 8, p. 241 - 246, 1997. 
CASETTI, Francesco. EI filme y su espectador. Madrid: Cátedra, 1994.

CASTELLANOS, Vicente. La experiencia estética en el cine: otros trayectos en los estudios cinematográficos. 2007.

DITTUS, Rubén. El dispositivo-cine como constructor de sentidos: el caso del documental político. Cuadernos.Info, Santiago, n. 33, p. 77 - 87. 2013. doi: 10.7764/cdi.33.532.

DOLL, Darcie. Escapar de los géneros entrando en ellos: una tendencia del cine Latinoamericano actual. Comunicación y Medios, Chile, n. 26, p. 51-59. 2012.

ECHEVERRI, Andrea. La producción de sentido en el cine. En: NIÑO, Douglas (coord.). Ensayos semióticos. Bogotá: Universidad Jorge Tadeo Lozano, 2008. p. 413-457

GARCÍA, Iridia; MENDOZA, María Inés. Retorica gramatical del cine de Román Chalbaud. Opción, Maracaibo, v. 21, n. 48, p. 34$56,2005$.

GARCÍA, Néstor. La épica de la globalización y el melodrama de la interculturalidad. En: MORAÑA, Mabel (ed.). Nuevas perspectivas desde/sobre América Latina: el desafío de los estudios culturales. Santiago: Editorial Cuarto propio, 2000. p. 3142.

GÓMEZ, Francisco Javier; ROSELLÓ, Roberto; GONZÁLEZ, Cristina. Los cines emergentes y la disonancia entre acción, política y elección estética en el cine latinoamericano: décadas 60 y 70 como paradigma. Comunicación y Medios, Chile, n. 24, p. $227-243,2011$.

GUILHERME, Sebastiao. Modelos del mundo moderno: hacia un consenso de imágenes en el cine de Latinoamérica. 
Latinoamérica, Ciudad de México, n. 47, p. 137-161, 2008.

LAVERDE, Alejandra; PARRA, Martha Ligia; URIBE, Yennifer. De la novela colombiana al cine. Anagramas, Medellín, v. 12, n. 24, p. 161-164, 2014.

LILLO, Gastón; CHACÓN, Albino. El cine Latinoamericano: del código realista al código postmoderno. Anclajes, La Pampa, v. 3, n. 2, p. 45-56, 1998.

LÓPEZ, Ricardo; VERGARA, Jorge. La metáfora del laberinto en el cine Latinoamericano actual. Revista 180, Santiago, n. 24, p. 60-73, 2009.

MANDOKI, Katya. Estética cotidiana y juegos de la cultura. Ciudad de México: Siglo XXI, 2006.

METZ, Christian. Ensayos sobre la significación en el cine (1964-1968). Barcelona: Paidós, 2002.

PARADA, Marcela. El estado de los estudios sobre cine en Chile: una visión panorama 1960-2009. Razón y Palabra, México, v. 6, n. 77 , p. $1-44,2011$.

RIVERA, Jerónimo. Reflexiones sobre la imagen del cine colombiano. Razón y Palabra, México, v. 6, n. 78, p. 1- 9, 2011.

ROJAS, Diego. Indagación diagnóstica sobre la investigación del cine colombiano: informe de consultoría. Bogotá: Ministerio de Cultura, 2009.

SALINAS, Claudio. Melodramas, identidades y modernidades Latinoamericanas en el cine actual: de amores perros a sábado. Aisthesis, Santiago, n. 48, p. 112 - 127, 2010.

STANGE, Hans; SALINAS, Claudio. Hacia una elucidación del 
campo de estudio sobre cine en Chile. Aisthesis, Santiago, n. 46, p. $270-283,2009$.

TORRES, Patricia. La memoria del cine como extensión de la memoria cultural, Culturales, Baja California, v. 2, n. 4, p. 50 79, 2006.

VALENZUELA, José Luis. En tránsito: desplazamientos Nimios en el cine Latinoamericano (2000-2010). Aisthesis, Santiago, n. 48, p. 141-154, 2011.

ZAVALA, Lauro. La traducción inter-semiótica en el cine de ficción. Ciencia ergo sum, Toluca, v. 16, n. 1, p. 47 - 54, 2009. 